\title{
Gastrointestinal Bleeding Is an Independent Risk Factor for Poor Prognosis in GIST Patients
}

\author{
Qi Liu, ${ }^{1}$ Yuji Li, ${ }^{1}$ Ming Dong, ${ }^{1}$ Fanmin Kong, ${ }^{1}$ and Qi Dong ${ }^{2}$ \\ ${ }^{1}$ Department of Gastrointestinal Surgery, The First Hospital of China Medical University, Shenyang, China \\ ${ }^{2}$ Department of General Surgery, The People's Hospital of China Medical University, Shenyang, China \\ Correspondence should be addressed to Qi Dong; dongqi@cmu.edu.cn
}

Received 2 March 2017; Accepted 13 April 2017; Published 15 May 2017

Academic Editor: Toshimi Chiba

Copyright (c) 2017 Qi Liu et al. This is an open access article distributed under the Creative Commons Attribution License, which permits unrestricted use, distribution, and reproduction in any medium, provided the original work is properly cited.

A retrospective analysis of prognosis of GIST was used to assess the prognostic effects of hemorrhage of digestive tract induced by mucosal invasion of primary gastrointestinal stromal tumors and related mechanisms. The conclusion is that GISTs with gastrointestinal hemorrhage are more likely to recur, which indicates poor prognosis. Therefore, gastrointestinal hemorrhage may be used as a significant indicator to assess the prognosis of patients.

\section{Introduction}

Gastrointestinal stromal tumor (GIST) is the most common soft tissue sarcoma in the digestive tract, and the stomach and small intestine are the most common sites. Liver metastases or peritoneal dissemination is the most common clinical malignant manifestations, but lymph node metastases are rare. Clinically, about $69 \%$ of patients with GIST are symptomatic, and gastrointestinal bleeding is the most common clinical symptom (in $30 \%-40 \%$ of cases) $[1,2]$. Many patients seek medical treatment due to gastrointestinal bleeding. There are also many cases of patients that suffer an uncontrollably massive hemorrhage of the gastrointestinal tract and require emergency surgery. Many studies have focused on the prognosis of GIST $[3,4]$.

Of the factors influencing the prognosis of patients with stromal tumors, high-risk factors for recurrence include tumor size $>5 \mathrm{~cm}$, mitotic count $>5$ counts per 50 highpower fields $(5 / 50 \mathrm{HPF})$, tumor rupture, postoperative recurrence risk $>50 \%[5,6]$, and the location of the tumor. The evaluation of malignancy differs between gastric and nongastric GIST even with equal tumor size and the same mitotic counts [7]. Studies [8,9] have shown that GIST is caused by mutations of the protooncogene c-KIT (60\%-80\%) or the platelet derived growth factor receptor (PDGFRA)
(10-20\%), suggesting the use for tyrosine kinase inhibitors (TKI) like imatinib mesylate for treatment of patients with GIST. The use of imatinib mesylate significantly improved the prognosis of patients with GIST, but the severe side effects and the high cost of these drugs limit widespread use. Therefore, it is necessary to select appropriate indicators to allow targeted therapy.

GIST tumor cells are thought to originate from Cajal cells [10], which are special cells that exist among smooth muscle cells. Exophytic growth, in which the tumor tends to grow outward beyond the surface of cells from which it originates, is the most common growth pattern of GIST. Tumor exophytic rupture can easily lead to abdominal metastasis. The National Comprehensive Cancer Network (NCCN) treatment guidelines and the National Institutes of Health (NIH) Risk stratification classify tumor rupture as a risk factor for recurrence but ignore another form of "rupture," gastrointestinal bleeding triggered by local mucosal ischemic necrosis due to the mucosal invasion, or extrusion by the tumor. However, there are only few studies of the influence of GIST induced gastrointestinal bleeding on prognosis. To address this problem, the aim of our study was to investigate the impact of gastrointestinal bleeding on the prognosis of GIST and its possible mechanisms. 


\section{Materials and Methods}

2.1. Materials. The clinical data of 301 patients with gastrointestinal stromal tumors treated surgically from September 2007 to March 2016 in the First Hospital of China Medical University were retrospectively analyzed. The inclusion criteria were as follows: (1) patients with primary gastrointestinal stromal tumors; (2) tumor diameter larger than $2 \mathrm{~cm}$; and (3) no other primary malignant tumors. Only 178 of the 301 patients met these inclusion criteria. Follow-up by telephone to the patient or family and data from our outpatient department were used to determine the condition and survival status of these patients. Overall, we were unable to determine the outcome for eight cases, but the remaining 170 cases were analyzed statistically; among the 170 cases, 134 patients' clinical data are complete.

2.2. Method. All GISTs were pathologically diagnosed. The statistical data included age, sex, time of onset, tumor location, tumor size, the stage according to the TNM Classification of Malignant Tumors (TNM stage), bleeding status, whether R0 resection was performed, mitotic count, and whether targeted therapy was performed after surgery. We determined whether the patients suffered gastrointestinal bleeding based on the following criteria: (1) endoscopic confirmation; (2) digital subtraction angiography (DSA) confirmation; (3) CT or E CT; (4) low HGB and haematemesis or being positive in $\mathrm{OB}$ test; or (5) the surgical record or pathological confirmation.

2.3. Statistical Analysis. Statistical analysis was performed using SPSS 13.0 software. The Pearson chi-square test was used to analyze the enumeration data and ranked data. The measurement data were analyzed by the independent sample $t$-test or the nonparametric rank sum test. Additionally, we selected the statistically significant factors and performed multivariate analysis using logistic regression. For prognostic analysis, we did a univariate analysis using Kaplan-Meier survival analysis to find the statistically significant data. This data was then subjected to multivariate analysis using the Cox regression model. We defined values of $P<0.05$ as statistically significant.

\section{Results}

3.1. Patient Information. The details of the patients in the study are presented in Table 1 . The dataset contained one hundred and seventy patients with 89 males and 81 females (ratio of male to female of about $1.1: 1$ ). There were 92 patients less than 60 years old and 78 patients at least 60 years old. The age distribution was from 25 to 82 years old with an average of 58.3 years old. Sixty-three of the patients had gastrointestinal bleeding that was due to mucosal rupture of the tumor. The other 107 patients showed no signs of gastrointestinal bleeding. There were 106 cases of the primary tumor located in a gastric site and 64 in a nongastric site. The tumor diameters ranged from $3 \mathrm{~cm}$ to $30 \mathrm{~cm}$ with an average value of $7.1 \mathrm{~cm}$. There were 59 cases of patients with a mitotic
TABLE 1: Clinical pathological characteristics of GIST patients.

\begin{tabular}{|c|c|}
\hline Parameters & Numbers \\
\hline \multicolumn{2}{|l|}{ Gender } \\
\hline Male & 89 \\
\hline Female & 81 \\
\hline \multirow{2}{*}{ Age (years) } & $25-82$ \\
\hline & $(58.27 \pm 10.54)$ \\
\hline \multicolumn{2}{|c|}{ Tumor site $(3-30 \mathrm{~cm}$; AVE $=7.1 \mathrm{~cm})$} \\
\hline Stomach & 106 \\
\hline Intestine & 64 \\
\hline \multicolumn{2}{|c|}{ Tumor size $(\mathrm{cm})$} \\
\hline$>5 \mathrm{~cm}$ & 86 \\
\hline$\leqslant 5 \mathrm{~cm}$ & 84 \\
\hline \multicolumn{2}{|l|}{ GI bleeding } \\
\hline+ & 63 \\
\hline- & 107 \\
\hline \multicolumn{2}{|l|}{ T stage } \\
\hline $\mathrm{T} 2$ & 85 \\
\hline $\mathrm{T} 3$ & 59 \\
\hline $\mathrm{T} 4$ & 26 \\
\hline \multicolumn{2}{|l|}{ M stage } \\
\hline Yes & 5 \\
\hline No & 165 \\
\hline \multicolumn{2}{|l|}{ Mitotic index } \\
\hline$>5 / 50 \mathrm{HPF}$ & 59 \\
\hline$\leqslant 5 / 50 \mathrm{HPF}$ & 77 \\
\hline \multicolumn{2}{|l|}{ R0 resection } \\
\hline Yes & 162 \\
\hline No & 8 \\
\hline \multicolumn{2}{|l|}{ CD117 } \\
\hline+ & 139 \\
\hline- & 5 \\
\hline \multicolumn{2}{|l|}{ CD34 } \\
\hline+ & 129 \\
\hline- & 12 \\
\hline \multicolumn{2}{|l|}{ Dog1 } \\
\hline+ & 130 \\
\hline- & 5 \\
\hline \multicolumn{2}{|c|}{ Adjuvant therapy } \\
\hline+ & 38 \\
\hline- & 80 \\
\hline
\end{tabular}

count greater than 5/50 HPF and 38 patients were treated with adjuvant therapy after surgery.

3.2. Factors Associated with Gastrointestinal Hemorrhage. The factors associated with gastrointestinal hemorrhage are presented in Table 2 . The single-factor chi-square test showed that the following factors were associated with gastrointestinal hemorrhage: tumor size $(P<0.001)$, tumor location $(P<0.001)$, tumor $\mathrm{T}$ stage $(P<0.001)$, tumor $\mathrm{M}$ stage $(P=0.006)$, whether $\mathrm{R} 0$ resection was performed $(P<$ $0.001)$, and positive expression of CD34 $(P=0.036)$. We 
TABLE 2: Factors associated with gastrointestinal hemorrhage.

\begin{tabular}{|c|c|c|c|}
\hline \multirow{2}{*}{ Parameter } & \multicolumn{2}{|c|}{ Stromal tumors with bleeding } & \multirow{2}{*}{$P$} \\
\hline & Yes & No & \\
\hline \multicolumn{4}{|l|}{ Gender } \\
\hline Male & 36 & 53 & \multirow{2}{*}{0.346} \\
\hline Female & 27 & 54 & \\
\hline Age (years) & $58.71 \pm 10.2$ & $58.01 \pm 10.8$ & 0.874 \\
\hline \multicolumn{4}{|l|}{ Tumor site } \\
\hline Stomach & 28 & 78 & \multirow{2}{*}{$<0.001$} \\
\hline Intestine & 35 & 29 & \\
\hline \multicolumn{4}{|c|}{ Tumor size $(\mathrm{cm})$} \\
\hline$\geq 5 \mathrm{~cm}$ & 51 & 35 & \multirow{2}{*}{$<0.001$} \\
\hline$<5 \mathrm{~cm}$ & 12 & 72 & \\
\hline \multicolumn{4}{|l|}{ T stage } \\
\hline $\mathrm{T} 2$ & 13 & 72 & \multirow{3}{*}{$<0.001$} \\
\hline $\mathrm{T} 3$ & 31 & 28 & \\
\hline $\mathrm{T} 4$ & 19 & 7 & \\
\hline \multicolumn{4}{|l|}{ M stage } \\
\hline Yes & 5 & 0 & \multirow{2}{*}{0.006} \\
\hline No & 58 & 107 & \\
\hline \multicolumn{4}{|l|}{ Mitotic index } \\
\hline$\geq 5 / 50 \mathrm{HPF}$ & 23 & 36 & \multirow{2}{*}{0.590} \\
\hline$<5 / 50 \mathrm{HPF}$ & 26 & 51 & \\
\hline \multicolumn{4}{|l|}{ R0 excision } \\
\hline Yes & 55 & 107 & \multirow{2}{*}{0.001} \\
\hline No & 8 & 0 & \\
\hline \multicolumn{4}{|l|}{ CD117 } \\
\hline+ & 56 & 83 & \multirow{2}{*}{0.157} \\
\hline- & 0 & 5 & \\
\hline \multicolumn{4}{|l|}{ CD34 } \\
\hline+ & 48 & 81 & \multirow{2}{*}{0.064} \\
\hline- & 8 & 4 & \\
\hline \multicolumn{4}{|l|}{ Dog1 } \\
\hline+ & 49 & 81 & \multirow{2}{*}{0.651} \\
\hline- & 1 & 4 & \\
\hline
\end{tabular}

subjected these statistically significant factors to multivariate analysis using logistic regression. The analysis suggested that the primary tumor location was an independent risk factor for gastrointestinal hemorrhage $(P=0.006)$ and GIST was more likely to cause gastrointestinal hemorrhage in the small intestine than in the stomach.

Univariate and multivariate analysis for the prognostic factors of patients with GI bleeding are shown in Table 3. The Kaplan-Meier survival curve is shown in Figure 1. The data suggests that tumor recurrence is related to the following factors: tumor size $(P<0.001)$, tumor T stage $(P<0.001)$, tumor $\mathrm{M}$ stage $(P=0.013)$, presence of bleeding $(P<0.001)$, and whether R0 resection was performed $(P=0.004)$. We analyzed these factors described using the COX regression model. The results indicated that gastrointestinal bleeding was an independent risk factor for recurrence (95\% CI: 1.105-4.919, RR: 2.332, $P=0.026)$.
The Kaplan-Meier survival curve (Figure 1) indicates that patient death is associated with tumor $M$ staging $(P=0.011)$, bleeding $(P=0.023)$, R0 resection $(P=0.024)$, and positive expression of CD34 $(P=0.007)$. Analysis of these factors using the COX regression model showed that gastrointestinal hemorrhage is an independent risk factor for patient death (95\% CI: 1.057-9.181, RR: 3.116, $P=0.039$ ).

A typical case of a gastric stromal tumor with gastrointestinal bleeding is shown in Figure 2. A gastric stromal tumor with a complete capsule is shown for comparison with a gastric stromal tumor with mucosal ulceration and digestive tract bleeding.

\section{Discussion}

Mutations of KIT and PDGFRA are the most common causes of GIST $[9,11]$, which can develop in any part of the gastrointestinal tract with a different prognosis dependent on the tumor location. Tumor size, mitotic numbers, and tumor location are the most common risk factors for GIST risk stratification and are used as prognostic factors [7, 12, 13]. However, current prognosis methods for GIST have low accuracy and additional indicators are needed. Our results showed that clinical or pathological features such as the location and the size of the tumor are important factors affecting the prognosis of the patients, consistent with the previously known risk factors. We also found that digestive tract hemorrhage plays an important role in influencing prognosis. In addition, this study also found that patients with gastrointestinal bleeding may require R0 excision and are more likely to have a high tendency for metastasis than nonbleeding patients, which may explain why gastrointestinal bleeding impacts prognosis.

Gastrointestinal bleeding is a relatively familiar clinical manifestation with an incidence rate of about $30 \%-40 \%$ $[1,2]$. In our study, patients with gastrointestinal bleeding accounted for about $37 \%$ of our patient set, consistent with the rate reported previous studies. The rupture of GIST will disseminate in the abdominal cavity, resulting in poor patient prognosis. Gastrointestinal bleeding caused by a tumor is one form of rupture. The rupture of digestive tract mucosa that is invaded by tumor can be considered as another form of tumor rupture, leading to the spread of tumor cells and thus affecting patient prognosis.

As we can see from Table 2, the $T$ stage and $M$ stage of the GIST were associated with gastrointestinal hemorrhage. To be more specific, GIST with higher $\mathrm{T}$ stage value was more likely to cause gastrointestinal hemorrhage. If there is a distant metastasis, the probability of gastrointestinal hemorrhage is dramatically increased, suggesting that gastrointestinal hemorrhage may be a significant factor inducing distant metastasis. In addition, the positive expression of CD34 $(P=0.064)$ has some significance. There was positive CD34 expression in $70 \%-80 \%$ of the GIST patients, consistent with use of the expression level of CD34 as an index to be applied early in the research and diagnosis of GIST. However, a potential relationship of CD34 expression to gastrointestinal hemorrhage requires additional study. 
TABLE 3: Univariate and multivariate analysis for prognostic factors of patients with GI bleeding.

\begin{tabular}{lccc}
\hline Parameters & Median recurrence (days) & $\begin{array}{c}\text { Univariate analysis } P \\
\text { (Kaplan-Meier) }\end{array}$ & $\begin{array}{c}\text { Multivariate analysis } \\
\text { hazard ratio (95\% CI) }\end{array}$ \\
\hline Gender (female/male) & $1563 / 1815$ & 0.883 & \\
Age $(>60 / \leqslant 60)$ & $1797 / 1658$ & 0.889 & \\
Tumor site (gastric/nongastric) & $1760 / 1706$ & 0.914 & $1.864(0.525-6.622)$ \\
Tumor size ( $>5 / \leqslant 5)$ & $1425 / 2076$ & $<0.001$ & $1.277(0.618-2.638)$ \\
T stage (T2/T3/T4) & $2082 / 1503 / 1164$ & $<0.001$ & $1.004(0.103-9.763)$ \\
M stage (M0/M1) & $1820 / 683$ & 0.013 & $2.332(1.105-4.919)$ \\
Bleeding (positive/negative) & $1366 / 1999$ & $<0.001$ & $0.649(0.083-5.043)$ \\
R0 resection (yes/no) & $1872 / 711$ & 0.004 & \\
Mitotic index per 50 HPF $(<5 / \geq 5)$ & $1700 / 1650$ & 0.154 & \\
CD117 (positive/negative) & $1685 / 1452$ & 0.799 & \\
CD34 (positive/negative) & $1697 / 919$ & 0.130 & \\
DOG1 (positive/negative) & $1660 / 760$ & 0.090 & \\
Targeted therapy (yes/no) & $1649 / 1937$ & 0.071 & \\
\hline
\end{tabular}

${ }^{*} P$-value is statistically significant; gastrointestinal hemorrhage is an independent risk factor.

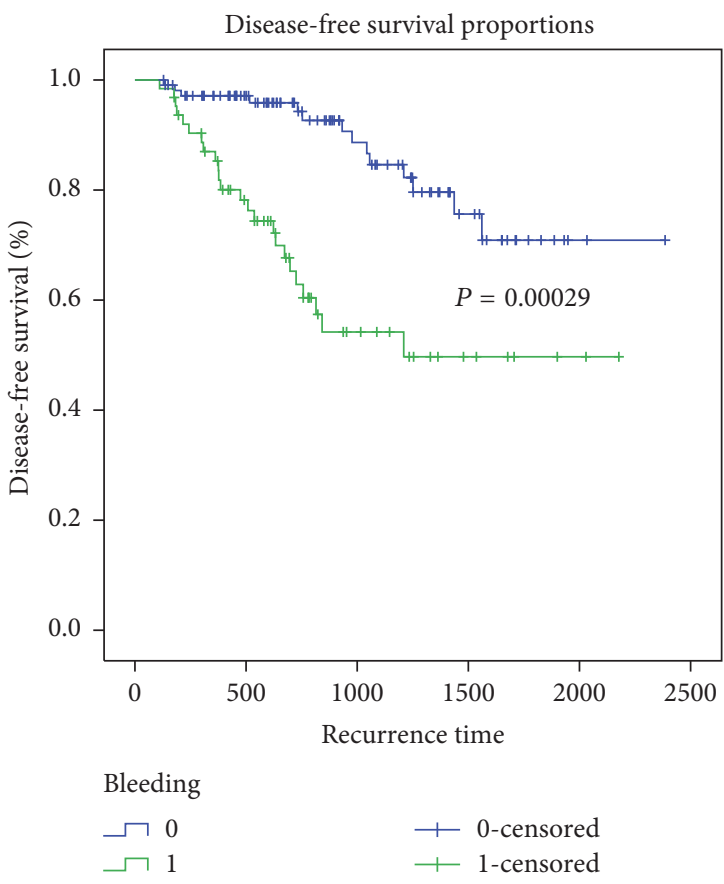

(a)

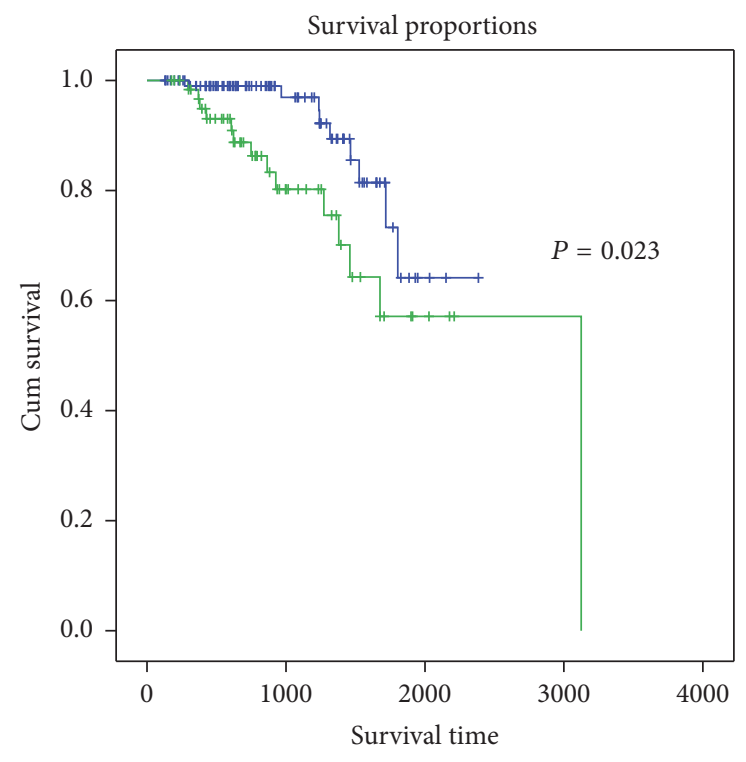

$\begin{array}{ll}\text { Bleeding } & \\ \neg 0 & +0 \text {-censored } \\ \neg 1 & +1 \text {-censored }\end{array}$

(b)

FIgURE 1: The Kaplan-Meier curve for GIST patients. (a) Recurrence time curve of the GIST patients with or without digestive tract bleeding. (b) Survival time curve for GIST patients with or without digestive tract bleeding.

Gastrointestinal bleeding caused by GIST may affect prognosis because growth of the tumor can restrict the digestive tract mucosa, resulting in altered local mucosal blood supply. As a result, cell necrosis causes barrier damage and, together with digestive juices, this can ultimately cause ulcerative bleeding. Another kind of hemorrhage may be induced by blood vessel rupture when the tumor invades and erodes the mucosal or submucosal blood vessels [14]. In our study, the 63 cases of gastrointestinal bleeding included 28 cases of gastric bleeding and 35 cases of nongastric bleeding, with incidence rates of $26.4 \%$ and $54.7 \%$, respectively. Comparing these incidence rates, we conclude that nongastric GIST was more likely to cause bleeding. Another study similarly reported that nongastric tumors are more inclined to evolve to necrosis [15]. Another possible explanation for these results is that the stomach is larger than the small intestine and other parts of the nongastric digestive tract, and the stomach is more resistant to extrusion by GIST. 


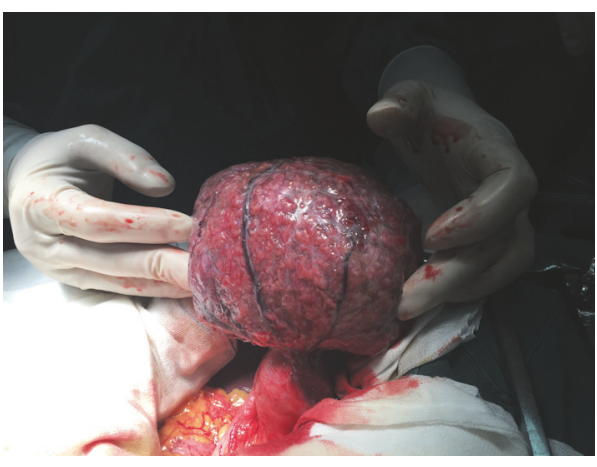

(a)

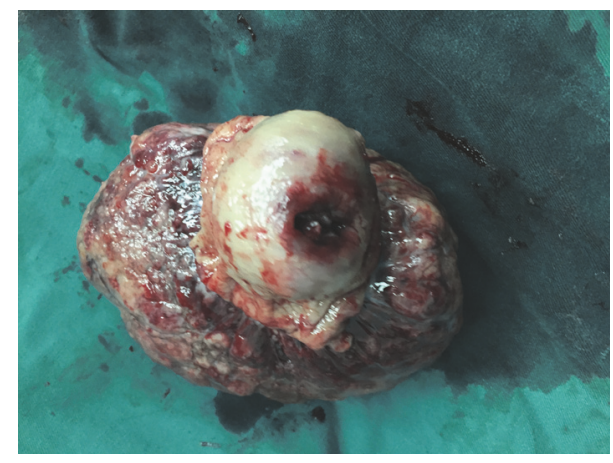

(b)

FIgURE 2: A typical case of gastric stromal tumor with gastrointestinal bleeding. (a) Gastric stromal tumor with a complete capsule. (b) Gastric stromal tumor with mucosal ulcer and digestive tract bleeding.

GIST has a certain malignant tendency but only requires a wedge resection or a partial resection to remove the tumor completely without lymph node dissection, unlike other digestive system malignant tumors [16]. However, even if the tumor is completely resected, the likelihood of recurrence or metastasis after surgery is about $40 \%-50 \%$ [17]. Before 2001, surgery was the only treatment for GIST with a fiveyear survival rate of around 50\% [18]. Recently, the use of TKI drugs like imatinib has improved patient prognosis and increased the probability of R0 resection [19]. However, it is worth pointing out that a GIST tumor is still likely to recur during the first 5 years after surgery, especially for patients in a high-risk group [20, 21]. Therefore, we should pay more attention to follow-up during this postsurgical period $[4,17$, 22]. Although there are some related studies [23], there are no risk stratification criteria that consider gastrointestinal bleeding caused by GIST as a significant indicator. The significance of studying the prognosis of gastrointestinal hemorrhage caused by GIST suggests that increased attention is warranted for follow-up of patients with gastrointestinal bleeding caused by GIST. Patients with bleeding should be considered to have higher risk level, and doctors should be aware of the postoperative recurrence risk and reduce the threshold of postoperative targeted therapy for patients with gastrointestinal bleeding.

The Kaplan-Meier curves show that both the recurrencefree survival and the overall survival are shorter for patients with gastrointestinal bleeding caused by GIST. Gastrointestinal bleeding is an independent risk factor for GIST recurrence and death of the patients and should be considered a significant indicator of poor prognosis.

\section{Conflicts of Interest}

The authors declare that they have no conflicts of interest.

\section{Acknowledgments}

This study was supported by the Scientific and Technological Projects from Shenyang Science and Technology Bureau, China (no. F13-221-9-54).

\section{References}

[1] B. Nilsson, P. Bümming, and J. M. Meis-Kindblom, "Gastrointestinal stromal tumors: The incidence, prevalence, clinical course, and prognostication in the preimatinib mesylate era-a population-based study in western Sweden," Cancer, vol. 103, no. 4, pp. 821-829, 2005.

[2] A. Rammohan, J. Sathyanesan, K. Rajendran et al., "A gist of gastrointestinal stromal tumors: a review," World Journal of Gastrointestinal Oncology, vol. 5, no. 6, pp. 102-112, 2012.

[3] G. A. Watson, D. Kelly, M. Melland-Smith et al., "Get the GIST? An overview of gastrointestinal stromal tumours," Irish Journal of Medical Science, vol. 185, no. 2, pp. 319-326, 2016.

[4] G. D. Demetri, M. M. Von, C. R. Antonescu et al., "NCCN task force report: update on the management of patients with gastrointestinal stromal tumors," Journal of the National Comprehensive Cancer Network, vol. 2, 8, no. 4, pp. S1-S44, 2010.

[5] C. D. M. Fletcher, J. J. Berman, C. Corless et al., "Diagnosis of gastrointestinal stromal tumors: a consensus approach," Human Pathology, vol. 33, no. 5, pp. 459-465, 2002.

[6] H. Joensuu, "Risk stratification of patients diagnosed with gastrointestinal stromal tumor," Human Pathology, vol. 39, no. 10, pp. 1411-1419, 2008.

[7] M. Miettinen and J. Lasota, "Gastrointestinal stromal tumors: pathology and prognosis at different sites," Seminars in Diagnostic Pathology, vol. 23, no. 2, pp. 70-83, 2006.

[8] B. P. Rubin, S. Singer, C. Tsao et al., "KIT activation is a ubiquitous feature of gastrointestinal stromal tumors," Cancer Research, vol. 61, no. 22, pp. 8118-8121, 2001.

[9] A. Kern, H. Görgens, D.-D. Dittert et al., "Mutational status of KIT and PDGFRA and expression of PDGFRA are not associated with prognosis after curative resection of primary Gastrointestinal Stromal Tumors (GISTs)," Journal of Surgical Oncology, vol. 104, no. 1, pp. 59-65, 2011.

[10] L. G. Kindblom, H. E. Remotti, and F. Aldenborg, "Gastrointestinal pacemaker cell tumor (GIPACT): gastrointestinal stromal tumors show phenotypic characteristics of the interstitial cells of Cajal," The American journal of Pathology, vol. 152, no. 5, pp. 1259-1269, 1998.

[11] S. Hirota, K. Isozaki, Y. Moriyama et al., "Gain-of-function mutations of c-kit in human gastrointestinal stromal tumors," Science, vol. 279, no. 5350, pp. 577-580, 1998. 
[12] M. Miettinen, "Gastrointestinal stromal tumors: review on morphology, molecular pathology, prognosis, and differential diagnosis," Archives of Pathology \& Laboratory Medicine, vol. 130, no. 10, pp. 1466-1478, 2006.

[13] A. D. Uçar, E. Oymaci, E. B. Carti et al., "Characteristics of Emergency gastrointestinal stromal tumor (GIST)," HepatoGastroenterology, vol. 62, no. 139, pp. 635-640, 2015.

[14] J. K. Trupiano, R. E. Stewart, C. Misick, H. D. Appelman, and J. R. Goldblum, "Gastric stromal tumors: a clinicopathologic study of 77 cases with correlation of features with nonaggressive and aggressive clinical behaviors," American Journal of Surgical Pathology, vol. 26, no. 6, pp. 705-714, 2002.

[15] B. K. P. Goh, P. K. H. Chow, W.-M. Yap et al., "Which is the optimal risk stratification system for surgically treated localized primary GIST? Comparison of three contemporary prognostic criteria in 171 tumors and a proposal for a modified armed forces institute of pathology risk criteria," Annals of Surgical Oncology, vol. 15, no. 8, pp. 2153-2163, 2008.

[16] M. Miettinen and J. Lasota, "Gastrointestinal stromal tumors," Gastroenterology Clinics of North America, vol. 42, no. 2, pp. 399-415, 2013.

[17] T. L. Frankel, A. E. Chang, and S. L. Wong, "Surgical options for localized and advanced gastrointestinal stromal tumors," Journal of Surgical Oncology, vol. 104, no. 8, pp. 882-887, 2011.

[18] R. P. DeMatteo, J. J. Lewis, D. Leung, S. S. Mudan, J. M. Woodruff, and M. F. Brennan, "Two hundred gastrointestinal stromal tumors: recurrence patterns and prognostic factors for survival," Annals of Surgery, vol. 231, no. 1, pp. 51-58, 2000.

[19] B. L. Eisenberg and I. Judson, "Surgery and imatinib in the management of GIST: emerging approaches to adjuvant and neoadjuvant therapy," Annals of Surgical Oncology, vol. 11, no. 5, pp. 465-475, 2004.

[20] H. Joensuu, M. Eriksson, K. Sundby Hall et al., "Adjuvant imatinib for high-risk GI stromal tumor: analysis of a randomized trial," Journal of Clinical Oncology, vol. 34, no. 3, pp. 244-250, 2016.

[21] S. J. Ford and A. Gronchi, "Indications for surgery in advanced/metastatic GIST," European Journal of Cancer, vol. 63, pp. 154-167, 2016.

[22] P. S. Sepe and W. R. Brugge, "A guide for the diagnosis and management of gastrointestinal stromal cell tumors," Nature Reviews Gastroenterology \& Hepatology, vol. 6, no. 6, pp. 363371, 2009.

[23] A. Lv, Z. Li, X. Tian et al., "SKP2 high expression, KIT Exon 11 deletions, and gastrointestinal bleeding as predictors of poor prognosis in primary gastrointestinal stromal tumors," PLOS ONE, vol. 8, no. 5, Article ID e62951, 2013. 


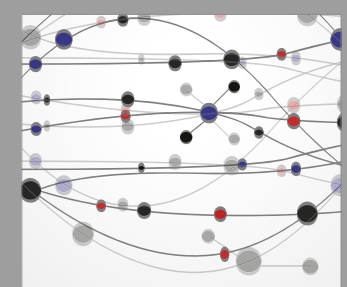

The Scientific World Journal
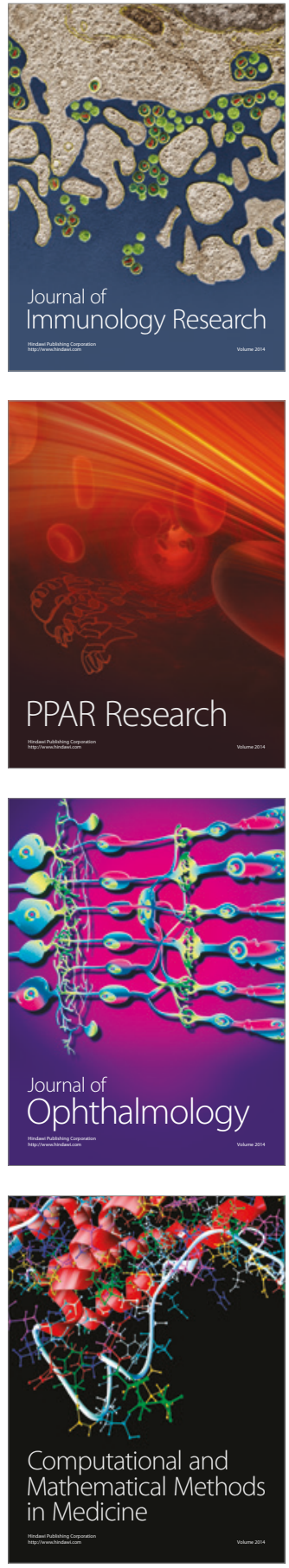

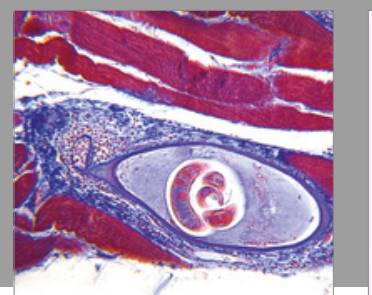

Gastroenterology Research and Practice
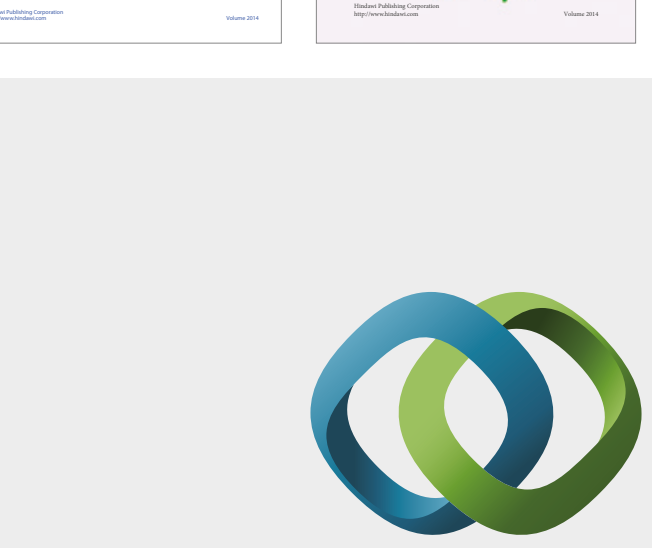

\section{Hindawi}

Submit your manuscripts at

https://www.hindawi.com
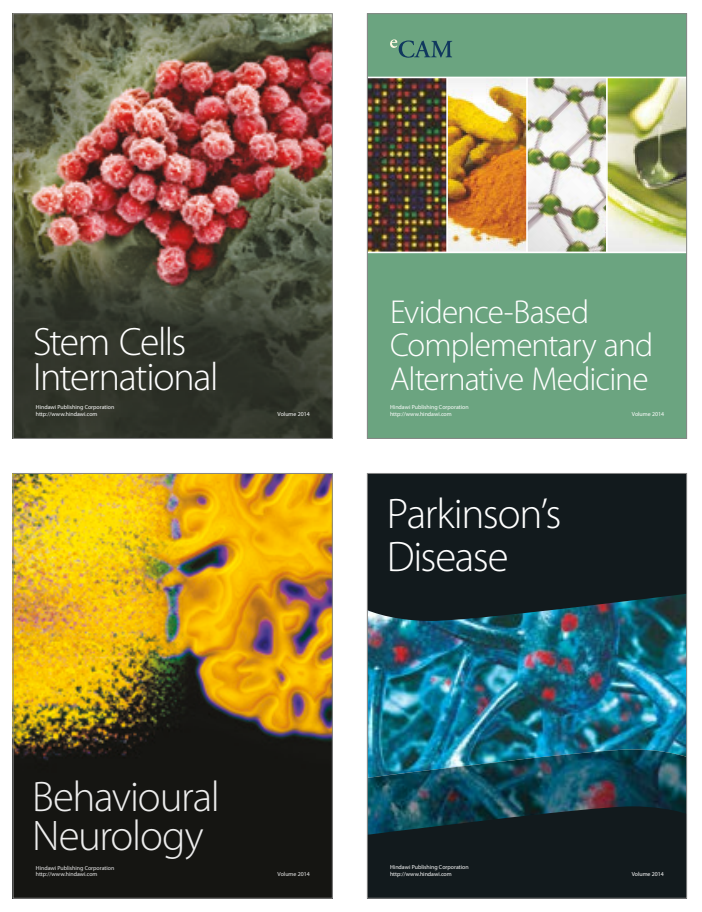
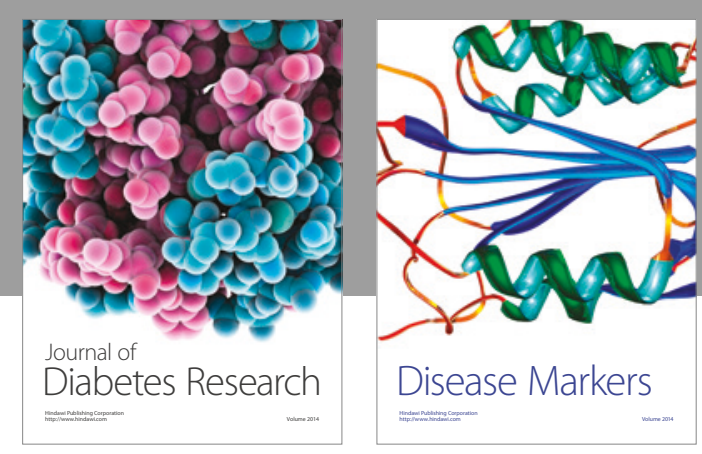

Disease Markers
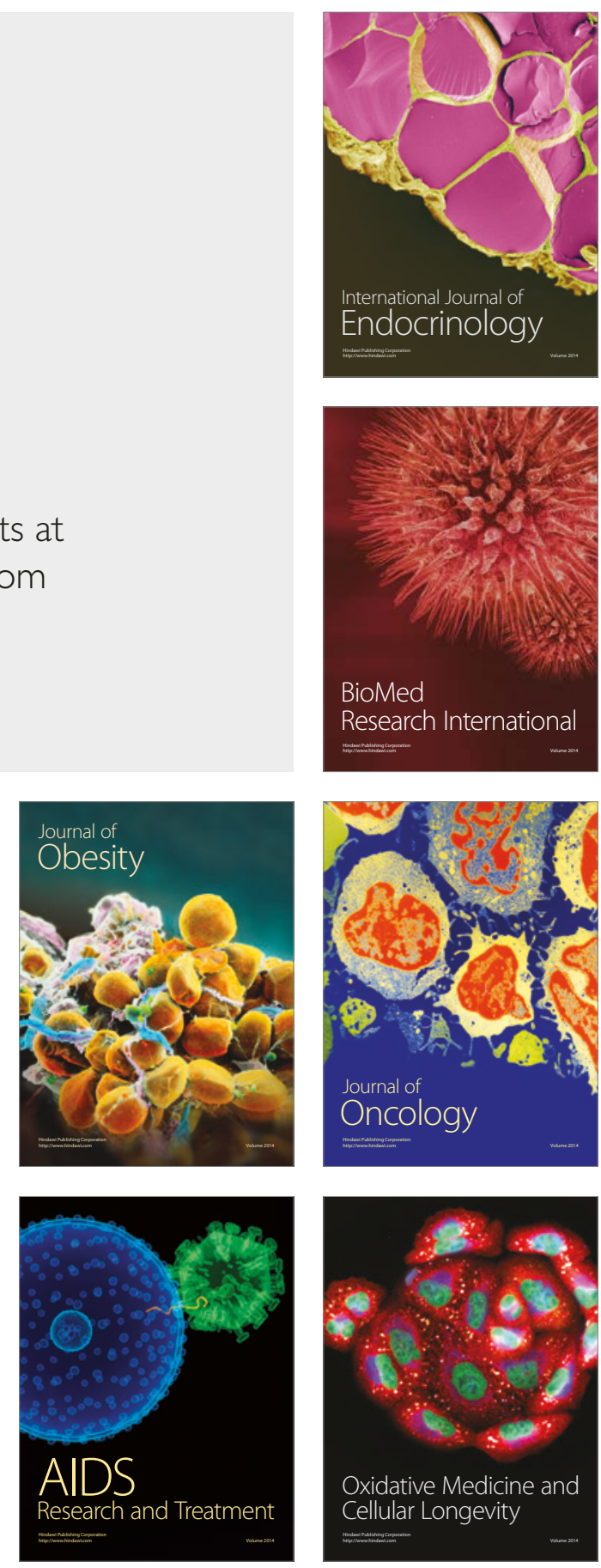